\title{
Farklı türlere ait yulaf (Avena spp.) aksesyonlarının genom büyüklüklerinin ve ploidi seviyelerinin belirlenmesi
}

\section{Determination of nuclear DNA content and ploidy levels of oat (Avena spp.) accessions belongs to different species}

\author{
M. Aydın AKBUDAK ${ }^{1,2}$, Ahmet PAKSOY ${ }^{2}$, Metin TUNA ${ }^{3}$ \\ ${ }^{1}$ Akdeniz Üniversitesi, Ziraat Fakültesi, Tarımsal Biyoteknoloji Bölümü, Antalya \\ ${ }^{2}$ Necmettin Erbakan Üniversitesi, Fen Bilimleri Enstitüsü, Moleküler Biyoloji ve Genetik Programı, Konya \\ ${ }^{3}$ Namık Kemal Üniversitesi, Ziraat Fakültesi, Tarla Bitkileri Bölümü, Tekirdağ \\ Sorumlu yazar (Corresponding author): M. A. Akbudak, e-posta (e-mail): akbudak@akdeniz.edu.tr
}

\section{MAKALE BİLGİİ}

Alınış tarihi 07 Ağustos 2017

Düzeltilme tarihi 27 Kasım 2017

Kabul tarihi 27 Kasim 2017

\section{Anahtar Kelimeler:}

Avena

Çekirdek DNA içeriği

Flow sitometri

Ploidi seviyesi

\section{ÖZ}

Genom büyüklüğü biyoloji, genetik, taksonomi ve evrim çalışmaları için son derece yararlı bir ölçüttür. Bu ölçüt türlere özel olduğundan, tür teşhisine ve gen bankalarında korunan genetik materyalin etiket bilgilerinin hızlı bir şekilde teyit edilebilmesine imkân sağlamaktadır. Bu çalışmada flow sitometri ile 13 farklı Avena türüne ait 64 aksesyonun ortalama genom büyüklüklerinin ve ploidi seviyelerinin belirlenmesi hedeflenmiştir. Analiz edilen A. brevis, $A$. hirtula, A. longiglumis, A. nuda, A. strigosa, A. ventricosa, A. abyssinica, A. barbata, A. murphyi, A. vaviloviana, A. fatua, A. sativa ve A. sterilis türlerine ait aksesyonların ortalama çekirdek DNA içeriklerinin 8.58 ile 26.54 pg/2C arasında değiştiği belirlenmiştir. Avena aksesyonlarının çekirdek DNA içerikleri arasındaki farklılık istatistiki olarak önemli bulunmuş ve aksesyonların ploidi düzeylerinin diploid ile hekzaploid arasında değiştiği saptanmıştır. Analizlerden elde edilen sonuçlar USDA-NSGC gen bankasında saklanan bu aksesyonlardan bazılarının etiket bilgilerinin doğru olmadığını ortaya çıkarmıştır. Literatürde mevcut çalışmaların sonuçlarından farklı olarak, incelenen dokuz A. brevis aksesyonunun DNA içeriklerinin 12.21-12.61 pg/2C aralığında olduğu tespit edilmiștir. Benzer șekilde, USDAGRIN sisteminde mevcut tek $A$. hirtula aksesyonunda daha önce yapılmış çalışmaların aksine çekirdek DNA miktarı $16.16 \mathrm{pg} / 2 \mathrm{C}$ olarak bulunmuştur.

\section{ARTICLE INFO}

Received 07 August 2017

Received in revised form 27 November 2017

Accepted 27 November 2017

\section{Keywords:}

Avena

Nuclear DNA content

Flow cytometry

Ploidy level

\begin{abstract}
Genome size is a good metric used in taxonomy and breeding studies for characterization of the genome and determination of evolutionary distances. It is mostly invariable within species; therefore, genome size estimations could be used for species identification and determination of genetic material integrity in germplasm collections. The present study targets verification of genome sizes and ploidy levels of 64 accessions classified in 13 Avena species using flow cytometry. Estimated nuclear DNA content of A. brevis, A. hirtula, A. longiglumus, A. nuda, A. strigosa, A. ventricosa, A. abyssinica, A. barbata, A. murphyi, A. vaviloviana, A. fatua, A. sativa ve $A$. sterilis accessions in this study ranged between $8.58-26.45 \mathrm{pg} / 2 \mathrm{C}$. It was found that nuclear DNA contents of the Avena accessions were statistically different, and ploidy levels of accessions are between diploid and hexaploid. Based on the data obtained from the flow cytometry analyses, it was concluded that some accessions were labelled wrongly in the USDA-NSGC collection. Contradicted from the studies in the literature, nuclear DNA content of nine A. brevis accessions were found between 12.21-12.61 pg/2C. Similarly, nuclear DNA content of the sole $A$. hirtula accession available in the USDA-GRIN system was found as $16.16 \mathrm{pg} / 2 \mathrm{C}$, which was reported differently in the previous studies.
\end{abstract}

\section{Giriș}

Genom büyüklüğü, bir organizmanın sahip olduğu replike olmamış haploid kromozom takımının içerdiği DNA miktarını ifade etmektedir (Swift 1950). Diploid $(2 \mathrm{n}=2 \mathrm{x})$ organizmalarda genom büyüklügü, haploid (n sayıda kromozom) sayıda kromozomun içerdiği DNA miktarını ifade etmektedir.
Ekmeklik buğday $(2 \mathrm{n}=6 \mathrm{x}=42)$ gibi üç farklı genoma $(\mathrm{ABD})$ sahip organizmalarda ise bu üç farklı genomu oluşturan kromozomların yarısındaki DNA içeriği genom büyüklüğünü verir. Genom büyüklüğü $\mathrm{C}$ değeri olarak ifade edilmekte olup, bu değer genomdaki DNA içeriğinin pikogram cinsinden 
miktarıdır. 2C değeri ise ploidi seviyesine bakılmaksızın, somatik bir hücrenin çekirdeği içerisinde bulunan DNA miktarıdır (Şakiroğlu ve Kaya 2012; Tuna 2014).

Türler arasında genom büyüklüğü ( $\mathrm{C}$ değeri) bakımından önemli düzeyde (yaklaşık 1000 kat) farklılıklar gözlenmektedir. Diğer taraftan bir türün farklı bireyleri arasında genom büyüklüğü değişmeden sabit kalmakta ve bu nedenle türlere özel olmaktadır (Bennett ve Leitch 1995). Bu nedenle, türlerin $\mathrm{C}$ değerleri biyoloji, genetik, taksonomi ve evrim çalışmaları için son derece önemlidir (Rees ve Walters 1965; Price and Bachmann 1975; Ohri 1998; Özkan ve ark. 2003).

Flow sitometri günümüzde genom büyüklüğünün belirlenmesinde kullanılan en yeni, hızl, hassas ve ekonomik metottur. Flow sitometri ile belirlenmiş $\mathrm{C}$ değerleri ile türlerin kromozom sayıları arasında çok sıkı bir ilişki olması nedeniyle bu parametre türlerin ploidi düzeylerinin belirlenmesinde de kullanılmaktadır (Tuna ve ark. 2001; Kaya 2010).

Gramineae familyası içerisinde yer alan Avena cinsine ait türlerin temel kromozom sayısı yedidir $(\mathrm{x}=7)$. Bu cins içerisinde ploidi düzeyleri diploid ile hekzaploid arasında değişen yaklaşık 30 tür yer almaktadır. Avena cinsi A, B, C ve D olarak adlandırılmış dört farklı genomu içermekte olup, diploid türlerin $A$ ya da $C$ genomlarına, tetraploid türlerin $A C$ ya da $A B$ genomlarına, hekzaploid türlerin ise ACD genomlarına sahip olduğu bilinmektedir. Bugüne kadar B ya da D genomunu taşıyan diploid bir yulaf türü henüz tanımlanmamıştır (Yan ve ark. 2016).

Avena cinsi sahip olduğu geniş tür ve genom çeşitliliği ile oldukça büyük bir genomik havuza sahiptir ve Avena türleri hastalıklara dayanıklılıktan verime kadar pek çok geni taşımaktadır (Loskutov 2008). Yabani türlerdeki bu genlerin tanımlanıp, kültür türlerine aktarılması yulaf ıslahı açısından oldukça önemlidir.

Yaygın olarak kültürü yapılan A. sativa (beyaz yulaf) ve $A$. byzantina (kırmızı yulaf) türleri, $2 \mathrm{n}=42$ kromozom sayısına sahip olan hekzaploid yulaf grubundadır (Erbaş 2012). Yulaf ( $A$. sativa) hem insan hem de hayvan beslenmesinde kullanılan önemli bir tahıl olup, dünyada ve Türkiye' de en çok üretilen altıncı tahıl türüdür (FAOStat 2014). Yüksek antioksidan içeriği ve suda çözünebilir lifli yapısı nedeniyle buğday, mısır, pirinç gibi klasik karbonhidrat kaynaklarına tercih edilen bir tahıl olarak yulaf, her geçen gün daha da ön plana çıkmaktadır (Wood 2001; Dokuyucu ve ark. 2002).

ABD' nin Idaho eyaletinde bulunan ABD Tarım Bakanlığı Ulusal Küçük Daneli Tahıllar Koleksiyonu (USDA-NSCG) 20000 'in üzerindeki Avena aksesyonu ile dünyadaki en büyük yulaf koleksiyonlarından birine sahiptir. $\mathrm{Bu}$ koleksiyonda, tanımlanmış yaklaşık 30 Avena türünden 13 tanesine ait aksesyonlar mevcuttur. Bununla birlikte nadiren de olsa USDAGRIN sisteminde bazı aksesyonların teşhisinin yanlış yapıldığı bildirilmiştir (Şakiroğlu ve Brummer 2011). Bu çalışmada USDA-NSGC koleksiyonunda mevcut olan Avena türlerinden, her türü temsil edecek şekilde rastgele seçilen 64 aksesyon kullanılmış olup, bu aksesyonların DNA içerikleri ve ploidi seviyeleri flow sitometri yöntemi kullanılarak belirlenmiştir.

\section{Materyal ve Yöntem}

Araştırmamızda dördü Türkiye'de de bulunan, toplamda 13 farklı Avena türüne ait 64 aksesyon kullanılmıştır. Tohumlar ABD Tarım Bakanlığı Ulusal Bitki Genetik Kaynaklar Sistemi (USDA-GRIN)' nden temin edilmiştir. Flow sitometri analizlerinde referans bitki olarak 2C DNA içeriği 3.65 pg olan adi fiğ (Vicia sativa) ile 10.65 pg olan arpa (Hordeum vulgare) kullanılmıştır. Tohumlar, içerisinde steril torf bulunan $7 \times 7 \times 7$ $\mathrm{cm}$ büyüklüğünde oyuklara sahip viyollere ekilmiş ve bitkiler analizler tamamlanana kadar plastik serada yetiştirilmiştir. Analizlerde 4-5 haftalık genç ve sağlıklı bitkilerden elde edilen yaprak dokuları kullanılmıştır. Çalışmada kullanılan Avena aksesyonlarının numaraları ve her aksesyon için analiz edilen bitki sayısı Çizelge 1'de verilmiştir.

Flow sitometri analizleri için örnekler CyStain PI Absolute P (Partec, Almanya) kullanılarak hazırlanmıştır. Sağlıklı yulaf ve referans bitkilerinden elde edilmiş $0.5 \mathrm{~cm}^{2}$ büyüklügündeki taze yaprak dokuları petri kaplarına yerleştirilerek üzerlerine $500 \mu \mathrm{l}$ izolasyon tamponu (buffer) ilave edilmiştir. Daha sonra yaprak dokuları keskin bir jilet ile 30-60 saniye süresince küçük parçalara ayrılana kadar parçalanmıştır. Örnekler petri kabı içerisinde 10-15 saniye çalkalandıktan sonra 30-90 saniye kadar bekletilmiş ve $50 \mu \mathrm{l}$ CellTrics filtre (Partec, Almanya) ile süzülerek tüplere transfer edilmiştir. Tüplere $2 \mathrm{ml}$ boyama solüyonu ilave edildikten sonra örnekler 1şıksız bir ortamda 3060 dakika inkübasyona bırakılmıştır. Örneklerin DNA içeriklerinin belirlenmesine yönelik ölçümler CyFlow Space (Partec, CY-S-3001) flow sitometre cihazında $488 \mathrm{~nm}$ dalga boyunda yapılmıştır (Tuna 2014). Ortalama DNA içeriği, 10000 çekirdeğin analiziyle belirlenmiştir. Çekirdek DNA içerikleri; örnekler ve standart bitkilerden elde edilen floresan yoğunluklarını kıyaslayan aşağıdaki formül ile hesaplanmıştır. DNA içeriklerine ait elde edilen değerler güven aralıklarını (confidence interval) kullanan basit bir istatistik prosedür ile kıyaslanmıştır (Steel 1960).

Örnek DNA miktarı= (Örnek bitkinin floresans yoğunluğu/ Standart bitkinin floresans yoğunluğu) x Standart bitkinin DNA içeriği

\section{Sonuçlar ve Tartışma}

İncelenen aksesyonların ploidi seviyelerini belirlemek için örneklerin floresans yoğunlukları, ploidi seviyeleri daha önceden bilinen arpa ve adi fiğ ile kıyaslanmıştır. Bunun için öncelikle bu iki türe ait bitkilerin floresans yoğunlukları tespit edilmiştir. Standartlar (diploid) için $150 \mathrm{~nm}$ dalga boyunda pikler elde edilmiştir. Yapılan tüm flow sitometri analizlerinden histogramlar elde edilmiş olup, diploid, tetrapoid ve hekzaploid türlerden birer örnek Şekil 1'de sunulmuştur.

Örneklerden elde edilen pikler ile standartlardan elde edilen pikler Şekil 1' deki gibi kıyaslanmıştır. Kıyaslama sonucunda aksesyonların diploid, tetraploid veya hekzaploid oldukları tespit edilmiştir (Çizelge 1).

\section{Aksesyonların DNA İçeriklerinin Belirlenmesi}

$\mathrm{Bu}$ çalışmada flow sitometri ile DNA içerikleri daha önceden bilinen arpa $(10.7 \mathrm{pg} / 2 \mathrm{C})$ ve adi fiğ $(3.65 \mathrm{pg} / 2 \mathrm{C})$ standart olarak kullanılmak suretiyle 13 Avena türüne ait 64 aksesyonun ortalama 2C çekirdek DNA içerikleri (genom büyüklükleri) başarılı bir şekilde belirlenmiştir. Elde edilen sonuçların CV değerlerinin \% 4' ten daha düşük olması yapılan analizlerin hassasiyetini göstermektedir. Çalışmada elde edilen sonuçlara göre, Avena aksesyonlarının 2C çekirdek DNA içeriklerinin 8.58 ile $26.54 \mathrm{pg}$ arasında değiştiği belirlenmiştir. Aksesyonlara ait çekirdek DNA içerikleri Çizelge 1'de ve farklı ploidi seviyesindeki üç örneğe ait flow sitometri histogramları Şekil 1'de sunulmuştur.

Yapılan analiz sonucunda incelenen aksesyonların çekirdek DNA içeriklerinin tür ortalamalarının 8.61-26.54 pg/2C 
Çizelge 1. Çalışmada kullanılan Avena aksesyonlarının çekirdek DNA içerikleri ve ploidi seviyeleri.

Table 1. Nuclear DNA content and ploidy levels of Avena accessions used in this study.

\begin{tabular}{|c|c|c|c|c|c|c|c|c|}
\hline \multirow{2}{*}{ Türler } & \multirow{2}{*}{$\begin{array}{c}\text { Ploidi } \\
\text { seviyesi }\end{array}$} & \multirow{2}{*}{$\begin{array}{c}\text { Aksesyon } \\
\text { No }\end{array}$} & \multirow{2}{*}{$\begin{array}{l}\text { Bitki } \\
\text { sayısı }\end{array}$} & \multirow{2}{*}{$\begin{array}{c}\text { Ortalama 2C } \\
\text { değeri (pg DNA) }\end{array}$} & \multirow{2}{*}{ Standart Sapma } & \multirow{2}{*}{$\mathbf{T} * \mathbf{S x}$} & \multicolumn{2}{|c|}{ Güven Aralığı (pg DNA) } \\
\hline & & & & & & & Alt & Üst \\
\hline A. brevis & $2 n=2 x$ & PI 158204 & 5 & 12.39 & 0.15 & 0.18 & 12.21 & 12.54 \\
\hline A. brevis & $2 n=2 x$ & PI 83719 & 5 & 12.36 & 0.13 & 0.15 & 12.21 & 12.49 \\
\hline A. brevis & $2 n=2 x$ & PI 266826 & 5 & 12.42 & 0.14 & 0.16 & 12.26 & 12.56 \\
\hline A. brevis & $2 n=2 x$ & PI 258545 & 5 & 12.48 & 0.17 & 0.20 & 12.28 & 12.65 \\
\hline A. brevis & $2 n=2 x$ & PI 258543 & 5 & 12.48 & 0.17 & 0.20 & 12.28 & 12.65 \\
\hline A. brevis & $2 n=2 x$ & PI 573533 & 5 & 12.49 & 0.17 & 0.19 & 12.29 & 12.66 \\
\hline A. brevis & $2 n=2 x$ & PI 258542 & 5 & 12.41 & 0.07 & 0.08 & 12.33 & 12.48 \\
\hline A. brevis & $2 n=2 x$ & PI 258544 & 5 & 12.48 & 0.07 & 0.08 & 12.40 & 12.55 \\
\hline A. brevis & $2 n=2 x$ & PI 119009 & 5 & 12.53 & 0.08 & 0.09 & 12.44 & 12.61 \\
\hline A. hirtula & $2 n=2 x$ & PI 657464 & 5 & 16.16 & 0.34 & 0.39 & 15.77 & 16.50 \\
\hline A. longiglumis & $2 n=2 x$ & Clav 9071 & 3 & 8.70 & 0.28 & 0.32 & 8.38 & 8.97 \\
\hline A. longiglumis & $2 n=2 x$ & Clav 9088 & 3 & 9.08 & 0.55 & 0.63 & 8.45 & 9.63 \\
\hline A. longiglumis & $2 n=2 x$ & Clav 9087 & 3 & 8.80 & 0.21 & 0.24 & 8.57 & 9.01 \\
\hline A. longiglumis & $2 n=2 x$ & PI 282730 & 3 & 8.92 & 0.27 & 0.31 & 8.61 & 9.19 \\
\hline A. longiglumis & $2 n=2 x$ & PI 367390 & 3 & 8.96 & 0.23 & 0.27 & 8.69 & 9.19 \\
\hline A. longiglumis & $2 n=2 x$ & Clav 9089 & 3 & 9.02 & 0.10 & 0.11 & 8.91 & 9.11 \\
\hline A. nuda & $2 n=2 x$ & Clav 9010 & 3 & 8.74 & 0.48 & 0.55 & 8.19 & 9.22 \\
\hline A. nuda & $2 n=2 x$ & Clav 9008 & 3 & 8.58 & 0.20 & 0.23 & 8.35 & 8.79 \\
\hline A. nuda & $2 n=2 x$ & Clav 9009 & 3 & 8.78 & 0.25 & 0.28 & 8.50 & 9.03 \\
\hline A. nuda & $2 n=2 x$ & Clav 9047 & 3 & 8.93 & 0.36 & 0.42 & 8.51 & 9.29 \\
\hline A. nuda & $2 n=2 x$ & PI 401795 & 3 & 9.00 & 0.36 & 0.41 & 8.59 & 9.36 \\
\hline A. strigosa & $2 n=2 x$ & Clav 1782 & 3 & 8.61 & 0.55 & 0.64 & 7.97 & 9.16 \\
\hline A. strigosa & $2 n=2 x$ & Clav 2520 & 3 & 8.64 & 0.36 & 0.42 & 8.22 & 9.00 \\
\hline A. strigosa & $2 n=2 x$ & Clav 7280 & 3 & 8.61 & 0.17 & 0.19 & 8.41 & 8.78 \\
\hline A. strigosa & $2 n=2 x$ & PI 131695 & 3 & 8.74 & 0.23 & 0.27 & 8.47 & 8.98 \\
\hline A. strigosa & $2 n=2 x$ & Clav 5082 & 3 & 8.67 & 0.08 & 0.09 & 8.59 & 8.75 \\
\hline A. strigosa & $2 n=2 x$ & Clav 2514 & 3 & 8.76 & 0.03 & 0.04 & 8.73 & 8.79 \\
\hline A. ventricosa & $2 n=2 x$ & PI 657338 & 3 & 9.81 & 0.17 & 0.20 & 9.61 & 9.98 \\
\hline A. ventricosa & $2 n=2 x$ & PI 657337 & 3 & 9.76 & 0.08 & 0.09 & 9.67 & 9.84 \\
\hline A. abyssinica & $2 n=4 x$ & PI 411313 & 2 & 16.54 & 0.00 & 0.00 & 16.54 & 16.54 \\
\hline A. abyssinica & $2 n=4 x$ & PI 411306 & 3 & 16.37 & 0.24 & 0.27 & 16.09 & 16.61 \\
\hline A. abyssinica & $2 n=4 x$ & PI 411169 & 3 & 16.41 & 0.14 & 0.16 & 16.26 & 16.55 \\
\hline A. abyssinica* & $2 n=4 x$ & PI 411314 & 3 & 24.98 & 0.25 & 0.28 & 24.70 & 25.23 \\
\hline A. abyssinica* & $2 n=4 x$ & PI 411150 & 3 & 25.48 & 0.19 & 0.22 & 25.27 & 25.67 \\
\hline A. barbata* & $2 n=4 x$ & PI 377777 & 5 & 12.83 & 0.06 & 0.07 & 12.76 & 12.89 \\
\hline A. barbata* & $2 n=4 x$ & PI 377779 & 5 & 12.91 & 0.09 & 0.10 & 12.80 & 13.00 \\
\hline A. barbata & $2 n=4 x$ & PI 337774 & 5 & 16.25 & 0.20 & 0.23 & 16.03 & 16.45 \\
\hline A. barbata & $2 n=4 x$ & PI 411376 & 5 & 16.55 & 0.24 & 0.28 & 16.27 & 16.80 \\
\hline A. barbata & $2 n=4 x$ & PI 411374 & 5 & 16.90 & 0.13 & 0.14 & 16.75 & 17.02 \\
\hline A. murphyi & $2 n=4 x$ & PI 657382 & 3 & 18.51 & 0.43 & 0.49 & 18.02 & 18.94 \\
\hline A. murphyi & $2 n=4 x$ & PI 657381 & 3 & 18.59 & 0.28 & 0.32 & 18.27 & 18.87 \\
\hline A. murphyi & $2 n=4 x$ & PI 657356 & 3 & 18.58 & 0.12 & 0.14 & 18.43 & 18.70 \\
\hline A. murphyi & $2 n=4 x$ & PI 657355 & 3 & 18.59 & 0.04 & 0.05 & 18.54 & 18.63 \\
\hline A. murphyi & $2 n=4 x$ & PI 657383 & 3 & 18.71 & 0.08 & 0.09 & 18.62 & 18.78 \\
\hline A. vaviloviana & $2 n=4 x$ & PI 412761 & 3 & 16.45 & 0.35 & 0.41 & 16.04 & 16.80 \\
\hline A. vaviloviana & $2 n=4 x$ & PI 412733 & 3 & 16.33 & 0.11 & 0.12 & 16.21 & 16.43 \\
\hline A. vaviloviana & $2 n=4 x$ & PI 412760 & 3 & 16.43 & 0.08 & 0.09 & 16.34 & 16.51 \\
\hline A. vaviloviana & $2 n=4 x$ & PI 412736 & 3 & 16.69 & 0.26 & 0.30 & 16.40 & 16.95 \\
\hline A. vaviloviana & $2 n=4 x$ & PI 412753 & 3 & 16.44 & 0.03 & 0.03 & 16.40 & 16.47 \\
\hline A. fatua & $2 n=6 x$ & PI 411471 & 5 & 25.40 & 0.47 & 0.54 & 24.86 & 25.87 \\
\hline A. fatua & $2 n=6 x$ & PI 411470 & 5 & 25.34 & 0.26 & 0.30 & 25.04 & 25.60 \\
\hline A. fatua & $2 n=6 x$ & PI 411477 & 5 & 26.09 & 0.77 & 0.88 & 25.20 & 26.85 \\
\hline A. fatua & $2 n=6 x$ & PI 411476 & 5 & 25.95 & 0.61 & 0.71 & 25.25 & 26.57 \\
\hline A. fatua & $2 n=6 x$ & PI 411472 & 5 & 26.15 & 0.76 & 0.88 & 25.28 & 26.91 \\
\hline A. sativa & $2 n=6 x$ & PI 411414 & 5 & 25.86 & 0.52 & 0.60 & 25.26 & 26.38 \\
\hline A. sativa & $2 n=6 x$ & PI 411402 & 5 & 25.81 & 0.33 & 0.38 & 25.43 & 26.14 \\
\hline A. sativa & $2 n=6 x$ & PI 411415 & 5 & 25.95 & 0.17 & 0.19 & 25.75 & 26.12 \\
\hline A. sativa & $2 n=6 x$ & PI 411407 & 5 & 26.40 & 0.44 & 0.51 & 25.90 & 26.84 \\
\hline A. sativa & $2 n=6 x$ & PI 411401 & 5 & 26.30 & 0.18 & 0.20 & 26.10 & 26.48 \\
\hline A. sterilis & $2 n=6 x$ & PI 412601 & 5 & 25.76 & 0.27 & 0.31 & 25.44 & 26.03 \\
\hline A. sterilis & $2 n=6 x$ & PI 412572 & 5 & 25.93 & 0.22 & 0.25 & 25.68 & 26.14 \\
\hline A. sterilis & $2 n=6 x$ & PI 412571 & 5 & 26.14 & 0.32 & 0.37 & 25.77 & 26.46 \\
\hline A. sterilis & $2 n=6 x$ & PI 412595 & 5 & 26.31 & 0.31 & 0.36 & 25.95 & 26.62 \\
\hline A. sterilis & $2 n=6 x$ & PI 412590 & 5 & 26.54 & 0.30 & 0.34 & 26.20 & 26.84 \\
\hline
\end{tabular}

*: Fiziksel karışıklık olduğu ya da tür tanımlamasında hata yapıldığı tespit edilen aksesyonlar. 

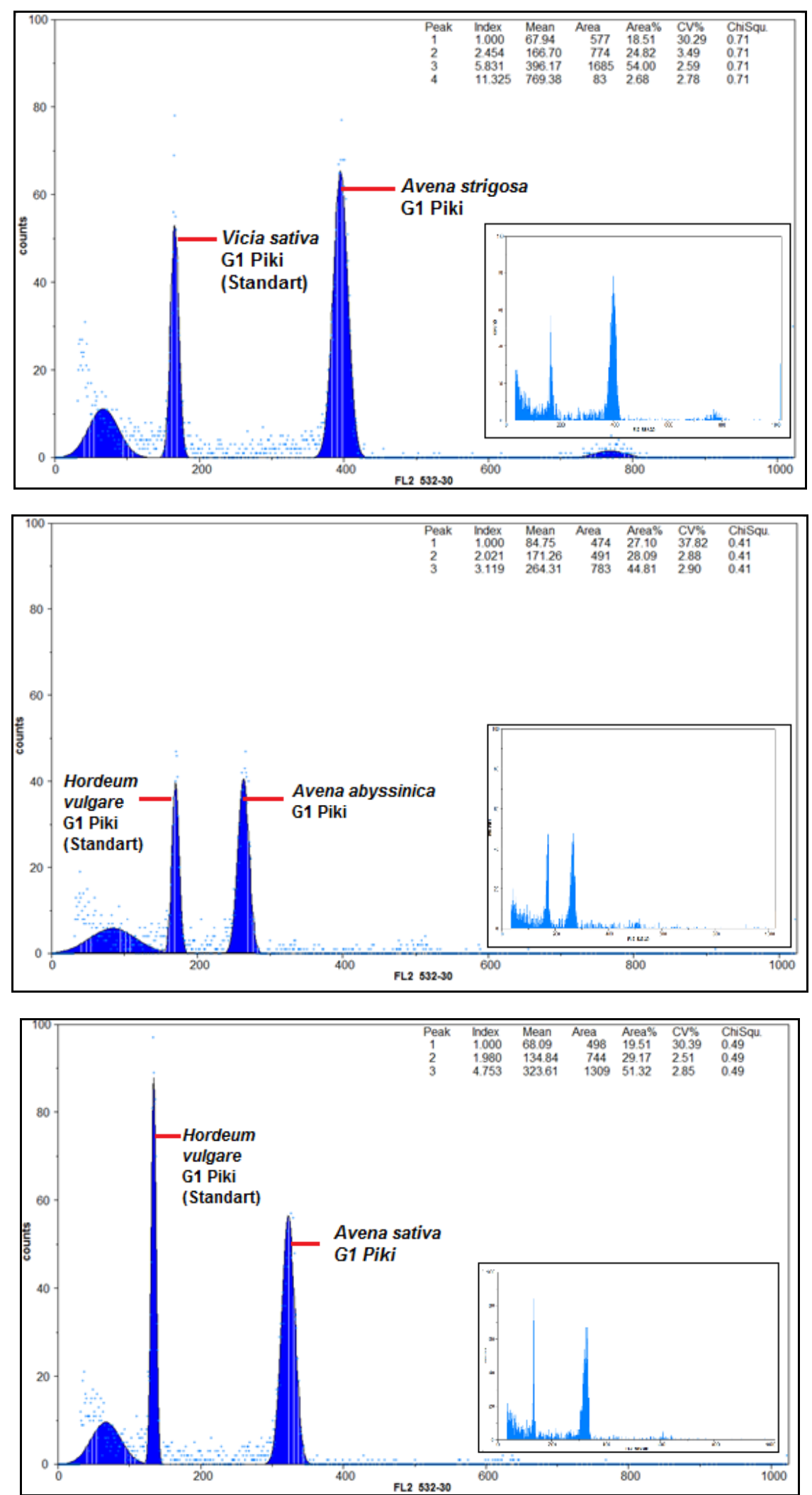

Şekil 1. Avena strigosa (diploid, A genomu), A. abbyssinica (tetraploid, AB genomu) ve A. sativa (hekzaploid, ABD genomu) türlerinden izole edilen propidiumiodide (PI) ile boyanmış hücre çekirdeklerine ait floresan histogramları. Arpa (Hordeum vulgare) ve adi fiğ (Vicia sativa) bitkileri kontrol olarak kullanılmıştır.

Figure 1. Fluorescent histograms of propidiumiodide (PI) dyed nuclei isolated from Avena strigosa (diploid, genome A), A. abbyssinica (tetraploid, genome $\mathrm{AB}$ ) and $\mathrm{A}$. sativa (hexaploid, genome $\mathrm{ABD}$ ). Barley (Hordeum vulgare) and vetch (Vicia sativa) were used as control. 
arasında değiştiği görülmüş olup, diploid türlerde DNA içeriğinin 7.99-12.53, tetraploid türlerde 6.37-18.71 ve hekzaploid türlerde ise 25.40-26.54 aralığında olduğu tespit edilmiştir (Çizelge 1).

Farklı bitki türlerinde yapılan çalışmalarda, gen bankasına koymadan önce türlerin fiziksel benzerlikler nedeniyle akraba türlerle karıştığı, yanlış tanımlandığı veya öncesinde ya da gen bankasında tutulduğu süreçte uğradıkları fiziksel karışma nedeniyle aksesyonların gen bankası veritabanında kayıtlı olan türle farklılıklar gösterdiği bildirilmiştir (Şakiroğlu ve Brummer 2011).

Alt ve üst değerler temel alınarak yapılan istatistiki analizde A. abyssinica da incelenen beş aksesyondan ortalama DNA içeriği bakımından üç tanesinin birinci grubu (PI 411313, PI 411306, PI 411169) ve diğer ikisinin ikinci grubu (PI 411314, PI 411150) oluşturacak şekilde farklı olduğu görülmüştür. İlk grubun DNA içeriği ortalaması $16.37-19.17$ pg olup, diğer grupta ise bu aralık 25.48-25.98 pg olarak tespit edilmiştir. Bu değerler A. abyssinica için Yan ve ark. (2016) tarafindan bildirilen 16.49-16.97 pg/2C DNA aralı̆̆ından farklılık arz etmekte olup, PI 411314 ve PI 411150 aksesyonlarının A. abyssinica türü içerisinde yer almadığına işaret etmektedir.

Aynı şekilde A. barbata' da analiz edilen 5 aksesyon, DNA içerikleri $12.83-12.91 \mathrm{pg} / 2 \mathrm{C}$ ve $16.25-16.90 \mathrm{pg} / 2 \mathrm{C}$ olan istatistiki olarak iki farklı grup (PI 377777, PI 377779 ve PI 337774, PI 411376, PI 411374) meydana getirmektedir. Daha önce yapılan dört farklı araştırma ile $A$. barbata için ortalama DNA içeriğinin 16.42-18.15 pg/2C olduğu bildirilmiştir (Çizelge 2). Bu sonuçlar, PI 377777 ve PI 377779 aksesyonları için USDA gen bankasında tohum karışıklığı olduğuna ya da yanlış tür teşhisinin yapıldığına işaret etmektedir.

Avena türlerinden bazılarının genom büyüklükleri flow sitometreye göre daha eski ve sonuçları daha az hassas olan Feulgen mikrodensimetre yöntemiyle üç farklı grup tarafından belirlenmiştir (Bullen ve Rees 1972; Iiyama ve Grant 1972; Bennett ve Smith 1976). Bullen ve Rees (1972) ve Iiyama ve
Grant (1972) tarafindan elde edilen sonuçlar daha sonra Bennett ve Smith (1976) tarafindan kalibrasyonu yapılarak tekrar yayınlanmıştır. Son olarak Yan ve ark. (2016) flow sitometre kullanarak 26 Avena cinsine ait 99 aksesyonun genom büyüklügünü belirlemişlerdir. Daha önce gerçekleştirilen bu dört çalışma ve bizim çalışmamızda bulunan sonuçlar karşılaştırmalı olarak Çizelge 2'de sunulmuştur.

$\mathrm{Bu}$ çalışma sonucunda; daha önceki çalışmalarda bulunan sonuçların (8.98-9.5 pg/2C) tamamından farklı olarak A. brevis' e ait incelenen dokuz aksesyonda çekirdek DNA miktarının 12.36-12.53 pg/2C aralığında olduğu tespit edilmiştir. Yine benzer şekilde A. hirtula da (USDA -NSGC' de mevcut tek aksesyon) çekirdek DNA miktarının $16.16 \mathrm{pg} / 2 \mathrm{C}$ olduğu; bunun da önceki çalışmalardaki $8.8-9.8 \mathrm{pg} / 2 \mathrm{C}$ aralığından oldukça farklı olduğu tespit edilmiştir.

İncelenen aksesyonlarda 10/64 (\% 16) oranında tohum karışıklığı ya da yanlış tür teşhisi yapıldığı, dolayısıyla bu aksesyonlara ait tohumların etiket bilgilerindeki türler olmadığ tespit edilmiştir. Bu durum - incelenen aksesyonlar göz önünde bulundurulduğunda - Avena türleri içerisinde tür içi varyasyonu ya da karışıklığı ifade etmektedir. Daha önce yapılmış çalışmalarla paralel olarak aynı ploidi düzeyine sahip türler arasında da çekirdek DNA içeriklerinin farklı olduğu, dolayısıyla Avena cinsine ait türlerde türler arası varyasyonun görüldüğü belirlenmiştir. Elde edilen verilerin sslah, taksonomi ve diğer çalışmalarda kullanılabileceği düşünülmektedir.

\section{Teşekkür}

Bu çalışma Necmettin Erbakan Üniversitesi Bilimsel Araştırmalar Fonu (Proje No: 161315001) tarafindan desteklenmiş ve Ahmet Paksoy' un yüksek lisans tezinde elde edilen veriler kullanılarak hazırlanmıştır. Gülru Yücel ve Taha Tangut' a teknik yardımlarından dolayı teşekkür ederiz.

Çizelge 2. Farklı çalışmalarda belirlenen Avena türlerine ait genom büyüklüklerinin karşılaştırması (pg/2C).

Table 2. Comparison of Avena genome sizes determined in this study and previous studies (pg/2C).

\begin{tabular}{|c|c|c|c|c|c|}
\hline & $\begin{array}{c}\text { Bu çalışmada } \\
\text { (In the present study) }\end{array}$ & Yan ve ark. (2016) & Bullen ve Rees $(1972)^{a}$ & Iiyama ve Grant $(1972)^{b}$ & Bennett ve Smith (1976) \\
\hline A. brevis" & 12.45 & 8.98 & $8.9(10.8)$ & - & 9.5 \\
\hline A. hirtula ${ }^{*}$ & 16.16 & 9.08 & $9.4(11.4)$ & 9.8 & 8.8 \\
\hline A. longiglumis & 8.91 & 9.23 & $9.9(12.0)$ & 9.8 & 10.6 \\
\hline A. nuda & 8.81 & 9.08 & $8.8(10.6)$ & - & - \\
\hline A. strigosa & 8.67 & 9.07 & $9.7(11.7)$ & 10.0 & 8.0 \\
\hline A. ventricosa & 9.78 & 10.29 & - & 10.9 & - \\
\hline A. abyssinica & 16.44 & 16.73 & $17.9(21.6)$ & 18.0 & 9.6 \\
\hline A. barbata & 16.25 & 16.42 & $18.5(22.4)$ & 18.1 & 17.8 \\
\hline A. vaviloviana & 16.47 & 16.38 & $17.0(20.5)$ & 18.4 & - \\
\hline A. fatua & 25.79 & 25.81 & $28.3(34.2)$ & 25.7 & - \\
\hline A. sativa & 26.07 & 25.70 & $27.5(33.2)$ & - & 26.5 \\
\hline A. sterilis & 26.13 & 25.75 & $28.6(34.5)$ & 28.2 & 27.3 \\
\hline
\end{tabular}




\section{Kaynaklar}

Bennett MD, Smith JB (1976) Nuclear DNA amounts in angiosperms. Philos. Trans. R. Soc. B Biol Sci. 274(933): 227-274.

Bullen MR, Rees H (1972) Nuclear variation within Avenae. Chromosoma 39(1): 93-100.

Dokuyucu T, Peterson DM, Akkaya A (2003) Contents of antioxidant compounds in Turkish Oats: Simple phenolics and avenanthramide concentrations. Cereal Chemistry 80(5): 542-543.

Erbaş O (2012) Yulaf (Avena sativa L.) genotiplerinin tarımsal ve bazı kalite özelliklerinin belirlenmesi. Yüksek Lisans Tezi, Bozok Üniversitesi Fen Bilimleri Enstitüsü, Yozgat, 1-4.

FAOStat (2014) F.A.O. Statistical databases. Food and Agriculture Organization of the United. http://www.fao.org/faostat/en/\#data/QC.

Iiyama K, Grant WF (1972) A correlation of nuclear DNA content and thin-layer chromatographic patterns in resolving genome relationships in Avena. Can. J. Bot. 50(7): 1529-1545.

Kaya M (2010) Medicago sativa ssp. varia populasyonlarının ploidi seviyesinin flow sitometri yöntemiyle belirlenmesi. Yüksek Lisans Tezi, Kafkas Üniversitesi Fen Bilimleri Enstitüsü, Kars, 9-11.

Loskutov IG (2008) On evolutionary pathways of Avena species. Genetic Resources and Crop Evolution 55(2): 211-220.

Ohri D (1998) Genome size variation and plant systematics. Annals of Botany 82: 75-83.

Özkan H, Tuna M, Arumuganathan K (2003) Non-additive changes in genome size during allopolyploidization in the wheat (AegilopsTriticum) group, 94(3):260-4.
Price HJ, Bachmann K (1975) DNA content and evolution in the Microseridinae. Amer. J. Bot. 62, 262267.

Rees H, Walters MR (1965) Nuclear DNA and the evolution of wheat. Heredity 20, Part 1, pp. 73-82.

Swift H (1950) The constancy of deoxyribose nucleic acid in plant nuclei. Proc Natl Acad Sci USA. 36(11): 643-654.

Steel RGD, JH Torrie (1960) Principles and Procedures of Statistics. (With Special Reference to the Biological Sciences.) McGraw-Hill Book Company, New York, Toronto, London.

Şakiroğlu M, Brummer EC (2011) Clarifying the ploidy of some accessions in the USDA alfalfa germplasm collection. Turkish Journal of Botany 35: 509-519.

Şakiroğlu M, Kaya M (2012) Estimating genome size and confirming ploidy levels of wild tetraploid Alfalfa accessions (Medicago sativa subsp. x varia) using flow cytometry. Turkish Journal of Field Crops 17(2): 151-156.

Tuna M, Vogel KP, Arumuganathan K, Gill KS (2001) DNA content and ploidy determination of bromegrass germplasm accessions by flow cytometry. Crop Sci. 41: 1629-1634.

Tuna M (2014) Bazı buğdaygil yem bitkisi türlerine ait populasyonların çekirdek DNA içeriklerinin flow sitometri yöntemiyle belirlenmesi ve poidy analizi ile tür teşhisinde kullanımı. 20.500.11776/2119.

Wood M (2001) New oats and barleys, ready for breakfast, brewery, or bran. Agricultural Research 49(8): 18-19.

Yan H, Martin SL, Bekele WA, Latta RG, Diederichsen A, Peng Y, Tinker NA (2016) Genome size variation in the genus Avena. Genome 59(3), pp. 209-220. 